\title{
Avaliação Microbiológica de Nutrição Enteral (Ne) em Hospitais Públicos
}

\author{
Priscilla Camilla Zucco dos Santos (I), Silvia Janine Veiga (I), \\ Rafaela Cardoso Gomes (I), Gilda Pinto Amaral (I), Victor \\ Alessandro Abib Pastore (I), Otávio Augusto Martins (I), Germano \\ Francisco Biondi (I) \\ (I) UNESP - Universidade Estadual Paulista (Distrito de Rubião Junior, s/n )
}

\section{Resumo}

A Nutrição Enteral (NE) é essencial aos pacientes que estão impossibilitados de se alimentarem através da via oral. A NE quando contaminada pode causar sérios danos à saúde do paciente. Assim, a NE pode ser uma das causas de infecção hospitalar. O objetivo consiste em avaliar a qualidade microbiológica de NE manipuladas em hospitais públicos na região noroeste do estado de São Paulo. No Laboratório de Microbiologia do SOAP - FMVZ - UNESP- Campus de Botucatu foram analisadas 175 amostras de NE, classificadas em Normocalórica (NOR), Hipercalórica (HIPER) e Específica para Diabéticos (ESP). Os organismos pesquisados foram as bactérias mesófilas aeróbias, coliformes a $35^{\circ} \mathrm{C}$ e a $45^{\circ} \mathrm{C}$, Staphylococcus coagulase positiva, Salmonella spp., Bacillus cereus, Clostridium sulfito redutor, totalizando 1.225 análises microbiológicas no período de 2013 a 2014. Na NE, 2,75\% de NORO, 6,82\% de HIPER e $8,33 \%$ de ESP apresentaram valores superiores a $103 \mathrm{UFC} / \mathrm{mL}$ de bactérias mesófilas aeróbias. Os valores superiores a $3 \mathrm{NMP} / \mathrm{mL}$ de coliformes a $35^{\circ} \mathrm{C}$ nas NEs foram de $4 \%$ para NOR; 5,68\% para HIPER e 16,67\% para ESP. Todas as amostras apresentaram resultados inferiores a $3 \mathrm{NMP} / \mathrm{mL}$ para coliformes a $45^{\circ} \mathrm{C} ; 3 \mathrm{UFC} / \mathrm{mL}$ para Staphylococcus coagulase positiva; $103 \mathrm{UFC/mL}$ para Bacillus cereus e para Clostridium sulfito redutor. Não foram detectadas a presença de Salmonella spp. nas amostras

\footnotetext{
Referência:

Priscilla Camilla Zucco dos Santos, Silvia Janine Veiga, Rafaela Cardoso Gomes, Gilda Pinto Amaral, Victor Alessandro Abib Pastore, Otávio Augusto Martins, Germano Francisco Biondi. Avaliação Microbiológica de Nutrição Enteral ( $\mathrm{Ne}$ ) em Hospitais Públicos. In: Anais do 12을 Congresso Latinoamericano de Microbiologia e Higiene de Alimentos - MICROAL 2014 [= Blucher Food Science Proceedings, num.1, vol.1]. São Paulo: Editora Blucher, 2014.

DOI 10.5151/foodsci-microal-161
} 
de NE. Para avaliar os resultados microbiológicos de NE foi adotado a RDC N 63 de 06/07/2000. A maioria das análises apresentou resultados satisfatórios com os padrões microbiológicos, servindo como indicativo da eficiência de boas práticas de preparação de NE em hospitais públicos da região noroeste do estado de São Paulo. Palavras chaves: Dieta Enteral; Microbiologia; Qualidade.

Palavras-Chave: Dieta Enteral, Microbiologia, Qualidade Agência de Fomento: 